\title{
Herding Effects, Over Confidence, Availability Bias and Representativeness as Behavioral Determinants of Perceived Investment Performance: An Empirical Evidence from Pakistan Stock Exchange (PSX)
} Hassan Javed ${ }^{1}$, Tanveer Bagh ${ }^{2 *}$ and Sadaf Razzaq ${ }^{3}$

${ }^{1}$ Army Pubic College of Management Sciences (APCOMS), University of Engineering and Technology, Punjab, Pakistan

${ }^{2}$ Department of Business Administration, Commerce Indus Group of Colleges, University of Azad Jammu and Kashmir, Pakistan

${ }^{3}$ Department of Management Sciences, University of Kotli, Pakistan

\begin{abstract}
The Behavioral Determinants (BD) of Perceived Investment Performance (PIP) are considered to be one of the most sizzling research concerns in the world of investment behavioral finance. Therefore, the main purpose of this study was to investigate the herding effects $(\mathrm{HE})$ over confidence $(\mathrm{OC})$ availability bias $(\mathrm{OB})$ and representativeness (R) [Independent Variables] as BD of PIP [Dependent Variable] in case of Pakistan stock exchange (PSX). Specifically, this study amid at to identify which biases impact more on PIP and to identify useful insights from the results of the study that may benefit in this discipline. Five likert scale questionnaire adapted from prior studies as it is satisfying the current scenario for industry settings of PSX. A quantitative cross sectional research design has been used in this study. The regression results found that the herding effects, over confidence, availability bias and representativeness have positive and significant impact on perceived investment performance. This study has significance for the individual investors, financial advisors, companies listed in PSX and Government. For the investors, the factors that influence their investment performance are crucial as these will influence their financial plans of future. Practical implications includes investors who desires to invest should incorporate the said BD for the accurate valuation of the assets and in taking future investment decisions. In PSX, it is first endeavor to uncover the HE, OC, AB and R as BD of PIP. This paper contribute to the existing body of literature since main stream of the previous studies concentrate more on the developed countries markets of the world. Moreover, this study put forth a well-integrated model to probe the effect of variables under consideration on PSX. Reflection of the said effect of behavioral impact in the decision making process of individuals will make the decisions more optimal and rational as well.
\end{abstract}

Keywords: Behavioral determinants; Herding effects; Over confidence; Availability bias and representativeness; Perceived investment performance; Pakistan

\section{Introduction}

In the field of Finance, investment Behavioral finance is regarded as an emerging discipline that incorporates behavioral biases and intellectual psychological elements accompanied with the economics and finance in order to draw viable supporting arguments for the irrational behaviors of people while making financial decisions. Both limits to arbitrage and cognitive processes are the cornerstone of behavioral finance. Cognitive psychological science deals with how people think [1]. Moreover, it is an emerging but rapidly expanding discipline of finance that tends to explain psychology-based theories to explain anomalies existing in the stock market on the basis of qualitative mental characteristics. In behavioral finance market outcome decisions are based on the structure of information and the attributes of market participants. The experts of sociology, economy and psychology have endeavored to explicate behavior of investor in numerous ways. Sociologists provided description on the behavior of investor by emphasizing on investors social environments. Economists or various field experts explored investor behavior while focusing primarily on the rational or irrational decisions of an investor. Psychologists have elaborated the behavior of investor by stressing on the individual characteristics that shape their decisions [2]. Interestingly, the participants of stock market have been relying on the idea that markets are always efficient and investors always tend to show rational decision making behavior. This idea seems quiet vague as all the investors do not possess estimation and analytical or computational capabilities that always maximize utility in making critical financial decisions. However, more than average number of investors cannot act rationally all the time as they are affected by their moods, emotions, beliefs that mislead them and also they have limited cognitive and computational capabilities so they mostly show irrational behaviors in order to make decisions easier [3]. Additionally, the broad environment of behavioral finance starts with the criticisms on the theories of standard finance which work contrary to the practical aspects of behaviors. The foundations of Standard finance lies in the theory of Efficient Market Hypothesis $(\mathrm{EMH})$ which states that investors are unbiased and rational all the time. This theory of pricing is based on information and the rational behaviors of investors. According to some researchers EMH assumes that the investors while making a rational investment decisions try to use all available information [4,5]. Moreover, recent researches in this field of finance also provide justification that investors exhibit deviation from rational behavior, showing irrational behavior and discrepancy due to uncontrollable behavioral factors like voracity, panic, emotions, conjecture and various other psychological biases during an investment decisions [5-7]. According to many research studies conducted in the

*Corresponding author: Tanveer Bagh, Department of Business Administration Commerce Indus Group of Colleges, University of Azad Jammu and Kashmir Pakistan, Tel: +923435886188; E-mail: tanveerbagh01@gmail.com

Received November 21, 2017; Accepted December 21, 2017; Published December 28, 2017

Citation: Javed H, Bagh T, Razzaq S (2017) Herding Effects, Over Confidence, Availability Bias and Representativeness as Behavioral Determinants of Perceived Investment Performance: An Empirical Evidence from Pakistan Stock Exchange (PSX). J Glob Econ 5: 275. doi: 10.4172/2375-4389.1000275

Copyright: (C) 2017 Javed $\mathrm{H}$, et al. This is an open-access article distributed under the terms of the Creative Commons Attribution License, which permits unrestricted use, distribution, and reproduction in any medium, provided the original author and source are credited. 
Citation: Javed H, Bagh T, Razzaq S (2017) Herding Effects, Over Confidence, Availability Bias and Representativeness as Behavioral Determinants of Perceived Investment Performance: An Empirical Evidence from Pakistan Stock Exchange (PSX). J Glob Econ 5: 275. doi: 10.4172/23754389.1000275

Page 2 of 13

initial years of this discipline also manifested the importance of behaviors in investment decisions $[8,9]$. Finance names these behavioral findings as anomalies in stock market and they have been named as anomalies due to no logical reasoning behind them according to standard finance [10]. Furthermore, the significance of psychological, emotional, and behavioral factors impacting the decision making of investors cannot be ignored. Behavioral finance is a relatively new and emerging field of study in the canvas of finance which predominantly focuses on the irrational decisions of investors and its effect on asset prices [11].

Probably, Behavioral finance has its roots in many behavioral theories which basically explain the individual behavioral biases according to its assumptions and impact on investment. This study mostly revolves around the Heuristics theory which states the shortcuts or rules of thumb which are used which making investment decisions. Heuristics is defined as a rule of thumb that facilitates decision making process by decreasing the convolution of evaluating probabilities and estimating values to simple decisions specially when encountered with complicated and tentative environments $[12,13]$. In the arena of behavioral finance Kahneman and Tversky [14] are the pioneer writers who studied the factors related to heuristics and found three most important factors like representativeness, availability bias, and anchoring.

\section{Stock Market-Importance in Research}

A market, where buying and selling of stock takes place is known as stock market $[14,15]$. Apart from playing the key role of financing investment in an economy, stock markets acts as a signaling bourse which effects the investment decisions, and is declared as a benchmark for corporate governance $[16,17]$. The success of the stock markets depends on the levels of controls activated in order to avoid noncompliance and violations and the trust of the investors. Zuravicky [15] stated that stock market is best source of capital for companies. Teweles and Bradley [18] stated that investors are interested in purchasing shares because of the growth opportunities, dividends, and safeguard against the inflation. According to Jaswani [19] liquidity feature of this market is the most important aspect which people consider before entering in it. Croushore [20] reported that people are attracted to this market because of ownership, capital gains and dividends yield features. According to Ngoc it is indeed worthwhile for investors to apprehend common behaviors that justify their reactions for better returns [21].

\section{Problem statement}

The problem statement is to be addressed in this study "the impact of investor behaviors on their investment performance perception as the behavioral" context of literature is majorly seen under uncertain situations and it is the real time when biases come into action. Current study considers four behavioral determinants (herding, over confidence, availability bias and representativeness bias) to explore their influence on perceived investment performance in collectivistic culture of Pakistan. There has been a good amount of research literature available on behavioral determinants of stock market investment performance in context of Western countries. It has also been documented in existing literature that individuals 'behavior varies from context to context. We cannot generalize any behavior by only seeing it in a specific geographical territory. It is a fact that behaviors differ on the basis of different societal distinctiveness possessed by local society. The societal factors have a strong impact on the citizens of society to an extent that they impact on the behaviors of the local people. Literature manifests that people brought up in Asian cultures are trapped by behavioral biases more, than in the Western cultures [21]. If we talk about Asian cultures, it tends to show collectivism [22]. And it is yet another truth that collectivist societies cause individuals to get trapped more by behavioral biases [1]

Sahi et al. [21] stated in their study that for getting proper acquaintance with behavioral finance, understanding of an investor's psychology plays critical role in knowing investment decision making patterns. The subject matter of perception is still very important in the field of behavioral finance as there is still no clear definition of risk in context of behavior [23-25]. Zhu [26] in his study found that biases impact on the investors risk perception because biases increase their satisfaction level. A behavioral finance expert, Montier [27] stated that the most miss understood concept of finance is Risk. Most of the investors possess tendency to be merely dependent on returns while very few take in to account that how risk impacts their overall financial goals. Perceived investment performance establishes a connection of person's choice with the acceptance or avoidance of risk while making decision under indeterminate consequences, thus influencing the investment performance [28]. After this long debate it is now clear that transactions of stocks are habitually supposed to be exuberantly influenced by irrational behavior, affecting the trading size and price of stock in the market. Elke and Richard [29] also asserted in their study that the stock buying decisions depends on the investor's perception. These researches confirm that biases don't directly influence the investment performance or decisions; rather they impact the perception of the investors. Lane and Quack [30] in his study came out with the most important aspect that Investors' perceptions of the riskiness of choice alternatives always show varying phenomena from one investor to the other depending upon person's belief and biasness. A research study found that even without having change in the fundamentals of the companies and the stock markets, the securities prices fluctuate on a daily basis showing the role of behaviors in investor decision [3].

The current study attempts to address the unexplored area of Pakistan where impact of behavioral factors on investment performance may be considerably higher than the Western countries due to collectivism. In collectivist culture peer pressure and social influence impacts on the investor decisions rather than the processing of market information. According to a study, it concluded that stock market investment is affected by social interaction [30]. The researchers in this study are of the view that individuals are trapped more by behavioral biases in collectivist cultures because of mimic behavior of individuals, social influence and family members or friends' pressure in making investment decisions. While talking about Pakistan, investors tend to invest if family members or friends are investing in stock market rather processing their private information. Particularly Pakistan as a collectivistic society the impact of behavioral biases should be more in affecting the investment decision making and shaping the stock market trends.

\section{Objectives of the Study}

\section{This research tailored to address following objectives;}

1. To explore the relationship between the biases and perceived investment performance of individual stock traders.

2. To identify which biases impact more on perceived investment performance.

3. To identify useful insights from the results of the study that may benefit in this discipline. 
Citation: Javed H, Bagh T, Razzaq S (2017) Herding Effects, Over Confidence, Availability Bias and Representativeness as Behavioral Determinants of Perceived Investment Performance: An Empirical Evidence from Pakistan Stock Exchange (PSX). J Glob Econ 5: 275. doi: 10.4172/23754389.1000275

Page 3 of 13

\section{Research Questions}

\section{The study research questions are presented below.}

1. Does herding impact positively on perceived investment performance?

2. Does overconfidence have a positive impact on perceived investment performance?

3. Does representative bias have a positive impact on perceived investment performance?

4. Does availability bias have a positive impact on perceived investment performance.

\section{Investor behavior a New Paradigm}

Behavioral Finance is defined as the study of the impact of psychology and cognitive factors on the behavior of financial practitioners' decision and the subsequent effect on markets (Sewell, 2010).

"Behavior of investor is a part of behavior finance, which seeks to understand and predict systematic financial market implications of psychological decision processes. Behavior finance closely combines individual behavior and market phenomena and uses knowledge taken from both the psychological field and financial theory" $[31,32]$.

The Figure 1 Behavioral Finance shows the components of the field of finance under consideration. All the three components are vital for this field of finance to understand the basics and emerging dimensions of markets and investors working in a close network.

After going through the past researches and study material of behavioral finance, it can't be assumed that the biases always result in losses. Investors need to know these factors in order to control them while making all crucial decisions. Shefrin [33] wrote a book on behavioral finance and EMH titled "Beyond Greed and Fear" that also stated that investors are imperfect evaluators of information so they show biased behavior and also result in perceptual constraints. Kahneman and Tversky $[14,34]$ also stated in their researches that most of the time investors are not rational regarding their decisions. According to Simon [35] investors have limited capacity of processing information in solving complex problems. Hence, conventional theories of finance may give incomplete and deceptive details of financial behavior. So we need not have waited for decades for this insight as the limitations of efficient market theory have ever been quite visible to those who wanted to look into it. Finance is now experiencing important changes, from

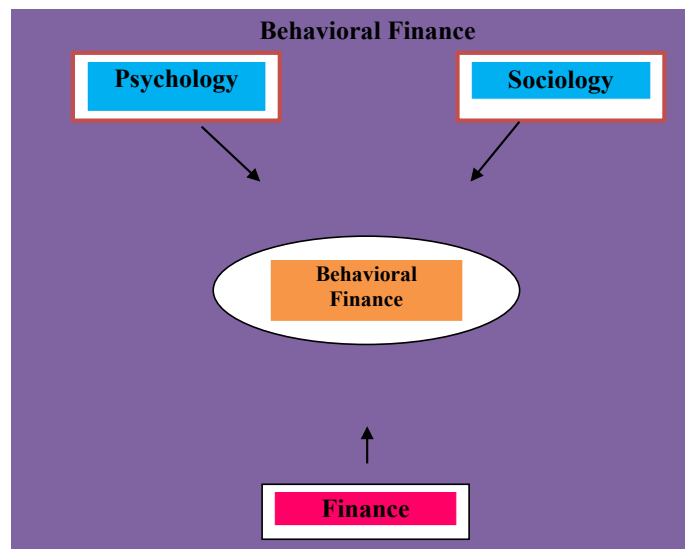

Figure 1: Behavioral finance. the traditional, neo classical mathematical modeling approach based on a representative, fully rational agent and perfect efficient markets to a behavioral approach based on computational models further based on bounded rational investors whose decisions are effected by their emotions, cognitive and behavioral biases, and social aspects and they use simple "rules of thumb" trading strategies $[35,36]$.

\section{Identification of Gap}

This type of research is being conducted on Pakistan Stock Exchange for the first time with the unique combination of variables based on literature. Pakistan Stock Exchange (PSE) has never been taken for behavioral finance study in this context. The uniqueness lies in the framework which is based on literature and intended to provide further in depth study on the most recent work done by the mentioned researchers in previous year. This study is basically to analyze and investigate broad objectives.to check the impact of behavioral biases on perceived investment performance in PSE and impact of perceived investment performance. Most of the studies in this area are done to analyze only the impact of biases on investment performance $[37,38]$. Earlier researchers worked on the behavioral determinants of investor's perceived investment performance and also incorporated the intervening role of perception but to a limited biases and suggested that in future, researches must be conducted to increase the scope of role in behavioral biases and investment performance [39]. Due to the limited role of behavioral biases, the researcher suggested further study on other biases and their relationship with investment performance. Qureshi et al. [40] worked on the relationship between behavioral biases and investment decisions and performance also suggested further study on behavioral biases like herding etc. and their impact on investment decisions and perceived performance.

Recent research finds out that there are some biases that influence investor decisions [33]. After that, large numbers of biases find out like cognitive bias, representative bias, overconfidence bias and loss aversion bias. Investors make judgment under uncertainty is re-analyzed with combined effect of some other biases. Investor's attitude towards gain and loss due to static differences across investors and Investor's psyche has strong effect on investment decision making in stock exchanges while making capital investment that is why they behave irrationally, emotions and psyche are major factors. Number of articles are published to study, analyze, and to inform investors that this is the fact that influence your decision. Aim of our study is to investigate the impact of Availability Biases (Heuristic bias) that refers as the situation when investors make decisions according to available information or Probability of events by available information and when relevance instances come to mind while decision making [40-42] and Loss aversion bias describes the behavioral biases with the effect of disposition (Prospect theory), risk and return paradox. Risk taking and risk aversion priorities vary from securities to securities It explains the behavior of investor become risk averse when prior return was above the target level and risk seeker in case of previous loss. This theory applies in different perspective when there are so many alternatives because decision makers are not constant in their preferences. One source of information availability is media advertisement and that make investors irrational by quickly reaction on it [25]. People judge the same event will fit into a given category due to similarity with prior happening that is why Investor's Risk taking and risk aversion priority strongly related with prior Losses and gain, it may cause risk assessment error, furthermore cognitive and emotional weakness plays vital role and effect of availability bias also described by Sewell [43]. Investors use mental short cut while making decisions and use probability of happening same event in future as 
Citation: Javed H, Bagh T, Razzaq S (2017) Herding Effects, Over Confidence, Availability Bias and Representativeness as Behavioral Determinants of Perceived Investment Performance: An Empirical Evidence from Pakistan Stock Exchange (PSX). J Glob Econ 5: 275. doi: 10.4172/23754389.1000275

Page 4 of 13

well. In this study we will see investor perception on the relationship of investment decision making, availability bias and loss aversion bias respectively. Risk in the modern world is perceived and acted upon in two fundamental ways. Risk as feelings refers to our instinctive and intuitive reactions to danger. Risk as analysis brings logic, reason, and scientific deliberation to bear on risk assessment and decision making. Sometime it effect investor to make positive relationship and maintain profit, while sometime investor loss high gains on little investment, so it's also effects negatively the investment decision making. Purpose of this study is to explore availability bias and loss aversion bias effect on investment decision making and whether perception of invertor effect the relationship or not. This study will help the investors to find out the reasons of irrational decision making due to Availability bias and loss aversion bias. It will help the researchers how these behavioral biases vary in collectivist and individualist cultures and impact on the psyche of developing countries like Pakistan. Prior researchers conducted studies on impact of Representative and Availability biases on investment decision in Individualistic dominated culture, but researchers in collectivist dominated countries are comparatively less concern about this cultural aspect in decision making. This study will fill this contextual gap in prior studies especially.

\section{Significance of the Study}

Our research is envisioned to escalate and broaden up the level of knowledge particularly regarding awareness and provide an understanding that investment or trading are driven by behavioral intentions, opposed to the basic motives that aid in conducting further studies through the provided research findings. Most imperative implication and significance of this study is that it is a way forward from the prior studies by behavioral scientists and researchers, making their efforts more beneficial. This study is a step ahead in determining the intervening role of perception between various behavioral biases and perceived investment performance. This research will be providing information, valuable for all kind of users and various researchers. Investors and stock house managers can use the knowledge in order to make the investors aware of their irrational behavior in order to control them. The findings may deliver in depth insights for PSE and policy makers as to how better performance of stocks can be achieved and in what way stock participation may be enhanced and ignited. This study has significance for the individual investors, financial advisors, companies listed in Pakistan's stock exchanges and Government. For the investors, the factors that influence their investment performance are crucial as this will influence their financial plans of future.

\section{Literature Review}

Herding or mimic behavior in stock markets is described as a behavioral tendency for an investor to follow the actions of other investor [44].

Herding is that behavior in which people will follow others in terms of their decisions and choices because of the ease they find rather processing their private information [45]. We cannot limit the scope of this behavior only to the finance discipline but it is a common behavior exhibited by people in social scenarios. Herding is one of the most commonly used biases especially talking within the scope of stock market and that's the reason why we have opted for this market to study this behavior. As Oberlechner and Osler [46] stated, excessively focusing that herding behavior is commonly highlighted in financial markets, showing that investors are drifted away by the actions of other people. As stock market is treated as the barometer of an economy so the stability of this market is of utmost importance. Herding bias comes into play under uncertainty and fear or when chances of taking own decision may result in huge losses, so the average investors make investment decisions by following others in order to gain more reliable information of the market. Kallinterakis et al. [47] mentioned in his study that following the noise bias is done by low ability investors who follow the investment decisions of more informed investors in order to gain good returns because of their limited financial knowledge. Tran [48] in his study investigated the impact of herding on the stock performance and found a very strong impact on the returns of the market. The herding bias is also related with the demographic characteristics of the investors like vast trading experience, good knowledge about the market and the ones who have good trading history. Apart from the demographic characteristics the behavior is majorly shown by the individual investors who have a limited reservoir of knowledge than the real field experts. This behavioral tendency creates a continuous volatility in stock prices due to quick reaction of masses towards a particular trend. From the past researches it has been proved that herding is mostly shown by Individual investor more than institutional investors because of the huge asymmetry of information that affects their risk appetite [49]. Among various determinants of herd behavior, some are very common which include investors' types, volume of stocks to trade and buying and selling of stocks. Another research study showed that herding is mostly used in buying and selling but choices of stocks and volumes of stocks to trade are less affected by herding [4]. Demirer and Kutan [2] worked on the relationship of herding and the investment returns and found that due to this behavior, volatility of the market is affected and this ultimately results in the impact on the investment performance. If market participants follow the masses' action, the volatility of returns might be forced, which results in destabilizing financial markets specifically during a crisis situations. According to Shleifer [50], there are three main factors involve in herding behavior, First, uncertainty leads to the copying what others do, Secondly, there is a relative performance reward system of bankers and investors and lastly there is more penalty being wrong alone rather than in company.

In addition, Researcher defined perceived risk as personal evaluation of riskiness of a situation in terms of probabilistic estimates [51]. Other researchers also focused on the factors that results in herding and they included riskiness of a situation and the volatility of stocks to be the two most important determinants [52]. Similarly when the investor wants to invest a large sum of capital then he/she tends to follow the other investor's actions to reduce the risks [37]. In stock market the reason for the deviation of prices from their fundamentals because of the over trading is a result of herding bias. This deviation from fundamental/ intrinsic value or market inefficiency does not explained by rational models of asset pricing explained in conventional finance. Stock price changes due to herding and also influences the characteristics of risk and return model of asset pricing [53]. In case of herding because of imitated masses' action, investors do not make informed decisions and also determination of their expected returns deviates from equilibrium model like Capital Asset Pricing Model [54]. In a study by Landberg [55] concluded that herding is done because of riskiness in a situation and the greed factor that ultimately results on the perceived investment performance. After analyzing the research literature regarding the role of risk perception between herding and investment performance, it is very clear that the literature also supports the hypothesis of this study.

\section{Hypothesis}

Hypothesis 1: Herding Bias has a positive significant impact on perceived investment performance. 
Citation: Javed H, Bagh T, Razzaq S (2017) Herding Effects, Over Confidence, Availability Bias and Representativeness as Behavioral Determinants of Perceived Investment Performance: An Empirical Evidence from Pakistan Stock Exchange (PSX). J Glob Econ 5: 275. doi: 10.4172/23754389.1000275

Page 5 of 13

\section{Over confidence}

The tendency of investors to either overestimate their abilities or underestimate other ability or difficulty of the task [56]. Trivial number of people ranked themselves in the below average category; nevertheless, as a matter of fact, fifty percent of the drivers are classified in the below average level. Several researches conducted in this aspect authenticated that people from the different fields such as: CEO of a company, lawyers, doctors, patients and students (propensity) overestimate their expectations regarding future [57]. In terms of investment, overconfidence appears to have a direct application, which is quite convoluted, involving future projection. The skills in recognizing the successful investment is perhaps misapprehended by overconfident investors. The propositions by traditional financial theory state to draft the diversified portfolio so that risk does not mount up to a specific area. Erroneous confidence can be of more worth against this advice, with investors certain about the positive projections of their investments, evoking them to think that diversification is needless. Overconfident investors consider having more power over the investment than what they actually have, demonstrating the association of overconfidence with control issue. Reported by one of the researches, wealthy investors claim that stock picking abilities were crucial to the performance of the portfolio. Whereas actually, investors had exceptional optimism about the stock performance they selected and misjudged the impact of the market as a whole on the performance of their portfolio [58]. Hence, investors overvalue their skills and the wider aspects that effect their investment are often neglected. There seems to appear a negative impact on the stock yield of the overconfident investors who trade exorbitantly. US investors with retail brokerage accounts were studied by professors Barber and Odean [59], representing that the lowest outcomes are faced by passionate traders. Overconfidence is also an attribute that influences an individual's risk perception as overconfident investors tend to make abrupt decisions, depicting their risk-taking behavior. According to researchers, overconfidence is among the greatest researched biases [60]. Saunders et al. [61] studied over confidence bias and found that overconfidence is responsible for the heightened level of trading activities and impacts on investment growth. According to a behavioral scientist, Confidence is a state of mind having full belief on ones abilities and on contrary overconfidence is explained by taking this belief to a maximum extent [62]. After studying the literature on over confidence; one can easily understand after comprehending studies, that this bias can impact the investor's risk perception and investment performance. Overconfidence not only improves persistence and determination but also the risk tolerance, which further can bring professional performance. Oberlechner and Osler [46] stated in their study that the investor who shows overconfidence bias can improve his impression as perceived by others, which results in greater investment duration and performance. Overconfidence means that a particular investor over emphasizes his private information and under emphasizes the public resources. Hence, the people overestimating the correctness of his own information despite of publically broadcasted information are supposed to be overconfident investors. Studies by Odean [63] provided further explanation and concluded that overconfidence induces more trading but decreases investment performance. On contrary a research study by Anderson, et al. [64] stated that the over confident investors make higher returns. So the research literature provides both the views regarding the impact of overconfidence on perceived investment performance. Michael [65] made it clear through the model that an investor thinks he is aware more than he requires and such misapprehension occurs when people lay plenteous consideration to their personal information. Certainly, over confidence is person's yearning to embellish his finding and forecasts. According to a study confidence provokes the investor to purchase a high priced stock and selling it at a low price that ultimately makes the investment performance to decline. Melissa et al. [41] stated that investors may overestimate or underestimate a given situation on the basis of the risk associated in it. So the bias is said to affect the investment performance indirectly, first effecting the risk perception than the investment performance. Sitkin and Pablo [45] investigated the over confidence bias in the study and found that when investors buy a stock showing overconfidence, they buy at higher price due to reduced risk estimate and later sell it on a lower price and book a loss in that transaction showing negative impact on performance. According to Zuravicky [15] overconfident investors trade at more frequent pace than rational investors because of the lower perceived risk and by doing so lowers their average utilities, meanwhile overconfident investors trade much aggressively after receiving information about the value of a stock and the study discovered a positive connotation between over confidence and performance of their stocks. Prolonged duration of efficacious investment decisions i.e. successful investment in a bull market, such as the real estate bubble followed by the 2008 Great Recession, intensified the feelings of extreme confidence. Research study by Bracha and Donald [66] indicated that overconfident investors focus more on the latest events and underestimate trivial probable risks that decrease risk perception of investment that further leads to heavy loss and confidence level influences the risk tolerance capacity of an investor. Van den Steen [67] contributed to the relationship of mounting feelings of perceived control i.e., over confidence escorted by decreasing perception of risk.

\section{Hypothesis}

Hypothesis 2: Over confidence has a positive significant impact on perceived investment performance.

\section{Availability bias}

In Availability Bias a decision maker relies upon knowledge that is readily available rather than examines other alternative and procedure. Decision makers in stock market are also influenced by the information they get during selection and identification of stock. Most of investors change their choice by keeping in mind their cost of capital. Investor preferences change according to available information and as a result in a particular leading pattern and sometime even irrelevant information also influence investment decision [67]. Here these irrelevance information effect investment decision making negatively, on the basis available information risk taking behavior of investor about particular security change the decision [68]. Several past studies say that investors feel comfortable in making decision based on if they have superior information [69]. When a firm in financial market reveal misconduct, the investor of that particular firm's stock get negative signal quickly and jump on the conclusion.

\section{Hypothesis 3}

Availability Bias has a positive significant impact on perceived investment performance.

\section{Representative bias}

Representativeness refers to the degree of similarity that an event has with its parent population [70] or the degree to which an event resembles its population [13]. The most generic financial illustration is that investors more probably suppose their investments to be valuable if the company is well reputed or renowned and handled in a fine way. It is somehow quite acceptable, yet the likelihood that the worth 
Citation: Javed H, Bagh T, Razzaq S (2017) Herding Effects, Over Confidence, Availability Bias and Representativeness as Behavioral Determinants of Perceived Investment Performance: An Empirical Evidence from Pakistan Stock Exchange (PSX). J Glob Econ 5: 275. doi: 10.4172/23754389.1000275

Page 6 of 13

of a company is signaled through the price of a stock and the future projections regarding return may be neutral is often overlooked. Further exemplification reveals the supposition that previous investment performance provides the clue for the future investment performance [1].

In behavioral finance another bias that impacts the investor's decision making and returns is representativeness which is a tendency to be more fascinated by the investments having good performance than the stock that performed poorly [71,72]. This bias deals with the stereotyping effect that investors mostly do in transactions of bourse. Investors on the basis of stereotyping, make investment decisions. An investor may categorize the securities with respect to their performance as strong, weak and good or poor. Stock market investors are affected by these biases and their investment decisions depicts all the biases which make them to move away from market rationality.

As stated by Tversky and Kahneman [73] behavioral finance field deals with the basic mental practices that we activate due to the indistinct rules declared as mental shortcuts, are the part of the decision making process. Investors showing heuristic, base their decisions on comprehensive generalizations of an asset, person or phenomena with respect to their superficial characteristics [74]. Similarly, Lin and Swanson [75] concluded in their study that stock market investors base their investment decisions on; volatility in the price index, recent price movement in a firms stock, economic indicators thus impacting on the investment performance.

Barber and Odean [59] investigated the impact of representativeness bias on their buying decisions and found that investors buy attention-grabbing stocks which manifested the significant impact of representativeness bias on the investment decisions. Due to the difficulty in searching among hundreds of stocks, investors tend to invest in the stocks that attract their attention. It is a natural instinct that being a human one makes use of mental shortcuts, resulting in complications to evaluate new information of investment precisely, deprived of biasness. Representativeness unleashes the idea that a participant of a category (e.g., risky behavior or hazardous activity) resembles others in the same class and which in return, resembles the source that created it. Busenitz [76] made an attempt to define the risk taking behavior of entrepreneurs who start a new business project, relating it to the cognitive psychology and decision making. The findings documented the use of representativeness to overcome their risk perception.

Research study conducted by Ritter [12] stated that investors of stock market emphasize much on recent investment experience and on the basis of that they often ignore the mean long-term return. A classic example of this bias is that investors often suppose a high longterm growth rate of a company after about quarters of increasing, hence estimating the behaviors of stocks on the basis of their trend [4]. Representativeness is also affected by sample size which leads to deduce from very few models [35]. Barber and Odean [59] also concluded that representativeness bias has a significant relationship with investment performance and explained that investors are attracted to the attention grabbing stocks that are in public media or has experienced high unanticipated trading quantity or stocks that have delivered good stock dynamics about returns thus transmitting a positive signal.

Bracha and Donald [66] in his study on New York stock exchange found that the representative bias impact the investment performance positively, people who follow the dimensions of this bias are often better off in terms of returns. On contrary found that investing on the basis of hot stocks, recent price fluctuations always result in accumulation of losses [77]. Merilkas and Prasad [78] explained the effects of representative bias which encourages them to miscalculate less prospect events, resulting in inappropriate decisions especially when decisions are related to risky assets investment. Sitkin and Pablo [45] also came up with the statement that when deciding about the potential investments, individuals are more biased in terms of strength of the source and observing patterns. They might suppose that the current movement in price will continue in the future as well. This encourages individual investors to allocate ample of attention to famous stocks that performed well recently. Busenitz [76] described that being tricked by the investment decisions based on the imperfect theory of insignificant numbers is something that can never be followed by a standard finance investor. In addition to, Busenitz [76] developed arguments that an investor concerning historical performance of a stock as an indication of future outcomes is a realistic likelihood, conflicting with the investor's standard finance model. Hence after evaluating the literature, we can assume that:

\section{Hypothesis}

Hypothesis 4: Representativeness bias has a positive significant impact on investment performance.

\section{Perceived investment performance}

Perceived investment performance is the self-analysis of the return on stock investment by the individual investment performance. Prior studies have worked on this area and found out that various behavioral biases impact the performance in positive and negative manner [77]. The shares with communal characteristics are being preferred that entice the institutional investors to pursue each other's investment decision in the stocks of any company [78]. In contrast, individual investors possess much propensity to follow the investment decision of a huge crowd of people in comparison to institutional investors [48]. Overconfident investors with excessive investment transactions approach could strike with an edge in the form of escalated outcomes [63]. In the long course of action overconfidence and under confidence both do not probably maintain the sustainability, though normal overconfidence can withstand and overshadow the sensible approach of an investor, validated by Wang [70].

Based on the inference of Anderson et al. [64], individuals with more frequent trading may clutch high yields as compared to those involved in limited trading. A stock with the enhanced individual possession may face consequences of negative irregular outcome, declared by Kim and Nofsinger [1]. Taking in consideration the three categories of earnings (raw returns, risk-adjusted returns, and momentum-adjusted returns) pertaining to the five time spans (daily, weekly, monthly, quarterly, annually), investment performance was estimated by Lin and Swanson [75]. Through this they exposed that as an investor one can attain superior performance, lasting only for short duration because in the long run or mid-term the outstanding performance dwindles away. Various level of influence of overconfidence on the performance of investment, evaluated by rate of return on investment and transaction involvement was accredited by Oberlechner and Osler [46]. Oberlechner and Osler [46] held a very profound opinion that return adhering to investment demonstrates the performance quantitatively. Investors most often perform calculations based on the profit earned in contrast to their companions. The time span of the existence of an investor in a stock market is reflected by his transaction involvement or knowledge. They explored and deducted that overconfidence does not stimulates the investment returns, anyways it does fuels the individual's transaction experience as shown in Figure 2. 
Citation: Javed H, Bagh T, Razzaq S (2017) Herding Effects, Over Confidence, Availability Bias and Representativeness as Behavioral Determinants of Perceived Investment Performance: An Empirical Evidence from Pakistan Stock Exchange (PSX). J Glob Econ 5: 275. doi: 10.4172/23754389.1000275

Page 7 of 13

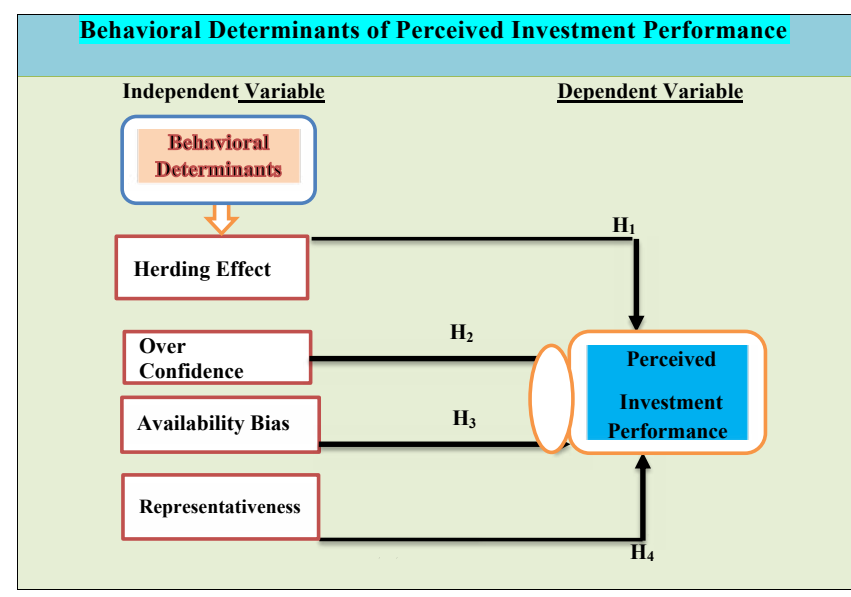

Figure 2: Theoretical framework.

\section{Gap analysis}

Most of the prior studies in this area were done to analyze only the impact of biases on investment performance and investment decisions [37]. The main objective of our study, under consideration is to examine the significance of investment performance in behavioral biases of investment performance in order to enhance the scope of research in this context. Despite of the existence of behavioral finance discipline, it is still new to the stock market. Most of the people, whether they are investors or academicians, have limited knowledge about behavioral finance; therefore, explanatory research has helped us to develop a clear understanding. Existing literature provided the foundation to propose the aforementioned hypotheses about investors' behaviors at the Pakistan Stock Exchange and further these hypotheses were tested with the help of data collected through questionnaires.

\section{Research Methodology}

\section{Research design}

A quantitative cross sectional research design has been used in this study. Quantitative study deals with measurable, quantitative properties of any phenomenon. This study is quantitative because data is collected from the population through questionnaire. The data was collected from the sample of population only at one time, so the research design of this study is cross-sectional in nature. This study is causal because the four independent variables are the factors (cause) which are affecting the investment performance decision (effect). We have applied a deductive approach; researchers on the basis of the existing theory propose their respective hypothesis and investigate them through empirical evidences. The staple objective of this study is to explain the relationship between behavioral determinants impacting the decision of investors, which is already being stimulated; hence deduction is the most suitable approach in this regard.

This study has adopted explanatory type of research. Explanatory research basically attempts to link ideas to comprehend cause and effect relationship. It sketches the way things are connected to one another and interaction between them. It was being conducted by the means of questionnaires, group discussions, interviews, random sampling, etc. The prime focus of the study is to apprehend the nature or type of relationship between the independent and dependent variables [79].

\section{Population and sampling strategy}

The population for this study is the total number of individual stock investors of Pakistan stock exchange (PSX) [80]. For the purpose of data collection, researchers have used the judgmental sampling technique. The main cause for this sampling technique is the low literacy rate prevailing in Pakistan due to which most of the investors are not aware of these technical terms. The intended sample size for this study will be set around 220 in order to get meaningful results. This sample size is fairly large comparative to the studies performed in this area. With the bigger sample size more reliable results are acquired [60]. This sample size was decided keeping in mind all the resources. Hair et al. [81] proposed that with the adoption of quantitative research, respondents should be more than hundred to have fit the statistical methods of data analysis.

\section{Unit of analysis}

The subject who is the primary unit of analysis of this research would be individual stock investors of Pakistan Stock Exchange. The subjects may include professionals of the field and may also include students working in stock market as their secondary source of income.

\section{Data collection and research instrument}

Primary data has been incorporated in our study. Primary data was gathered through adapted questionnaires designed for (PSX). The research instrument that we have used in our study is a Questionnaire. It was adapted from prior studies as it is satisfying the current scenario for industry settings of Pakistan Stock Exchange. The reason for the selection of this method is that the research questions are defined more appropriately. Additionally, questionnaire is the finest method to obtain standardized data that is easy to process and analyze. Table 1 shows that in the absence of interviewers the results are often unbiased and it is inexpensive and economical than other methods [81].

\section{Results and Discussions}

For the purpose of data collection of this study, individual investors were selected in order to comprehend our theories on this segment of the market. 220 questionnaires were distributed to stock houses, varying number of questionnaires were distributed in the brokerage houses on the bases of clientele. Out of 220 questionnaires we received 189 questionnaires with a response rate of questionnaires are $86 \%$. The researchers have applied multiple analytical tests so that the fitness of the model can be tested. Further in the process of normalization of the data many instruments were discarded due to abnormality in the data. Remaining instruments were used to analyze several tests for the fitness of theoretical framework and acceptance/rejection of our hypothesis.

\section{Demographic analysis}

From the Table 2 Gender it is evident that out of 189 respondents 181 respondents were male with a percentage of $95 \% .8$, and 8 were female having a percentage of $4.2 \%$.

From the Table 3 Employment Status it is evident that out of 189 respondents 42 respondents were employed with a percentage of $22.2 \%$.

\begin{tabular}{|c|c|}
\hline \multicolumn{2}{|c|}{ Statistical Tests To be applied } \\
\hline Pilot survey Test & Reliability Testing \\
\hline Normality of data & Pearson's Correlation \\
\hline Descriptive analysis & Regression assumption's tests \\
\hline Content Validity Testing & Regression Analysis \\
\hline
\end{tabular}

Table 1: Statistical tests. 
Citation: Javed H, Bagh T, Razzaq S (2017) Herding Effects, Over Confidence, Availability Bias and Representativeness as Behavioral Determinants of Perceived Investment Performance: An Empirical Evidence from Pakistan Stock Exchange (PSX). J Glob Econ 5: 275. doi: 10.4172/23754389.1000275

Page 8 of 13

\begin{tabular}{|c|c|c|c|c|}
\hline & Frequency & Percent & Valid Percent & Cumulative Percent \\
\hline \multicolumn{5}{|l|}{ Valid } \\
\hline Male & 181 & 95.8 & 95.8 & 95.8 \\
\hline Female & 8 & 4.2 & 4.2 & 100 \\
\hline Total & 189 & 100 & 100 & - \\
\hline
\end{tabular}

\begin{tabular}{|l|c|c|c|c|}
\hline & Frequency & Percent & Valid Percent & Cumulative Percent \\
\hline Employed & 42 & 22.2 & 22.2 & 22.2 \\
\hline Un employed & 96 & 50.8 & 50.8 & 73 \\
\hline Self employed & 51 & 27 & 27 & 100 \\
\hline Total & 189 & 100 & 100 & - \\
\hline
\end{tabular}

Table 3: Employment status.

\section{Normal P-P Plot of Regression Standardized Residual}

Dependent Variable: PIP

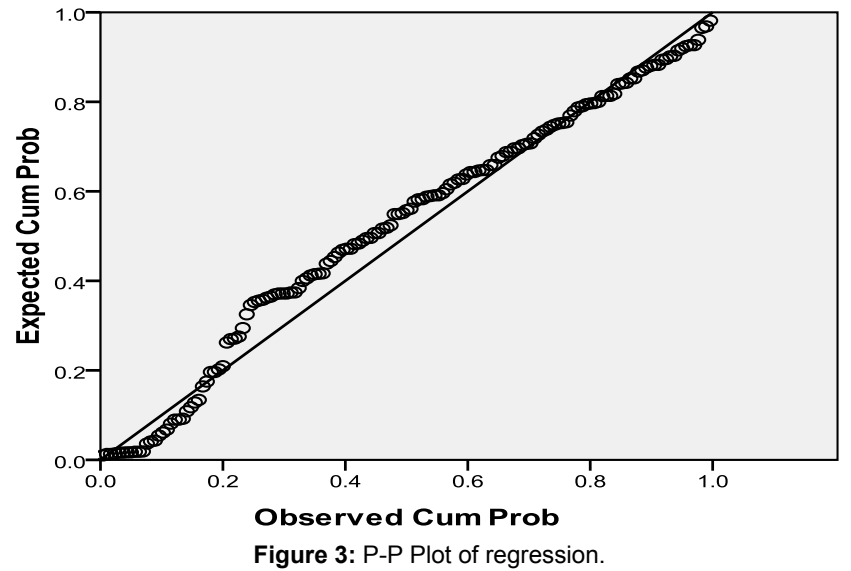

96 were unemployed with $50.8 \%$ and 51 were Self-employed with $27 \%$. Below Figure 2 is the graphical representation of the table.

From the above Table 4, it is evident that out of 189 respondents 32 respondents were having age fell in between $26-33$ with a percentage of $16.9 \%, 61$ fell in between $34-41$ with a percentage of $32.3 \%$, 65 were having an age between $42-49$ with a percentage of $34.4 \%$ and 31 were having an age 50 above with a percentage of $16.4 \%$. Below Figure 3 is the graphical representation of the table.

From the above Table 5, it is evident that out of 189 respondents 82 respondents were having education of matriculation with percentage of 43.4. 72 having Bachelors education with a percentage of $38.1 \%$ and 35 having Masters Education with a percentage of 18.5\%. Below Figure 3 is the graphical representation of the table.

From the above Table 6, it is evident that out of 189 respondents 19 respondents were having experience in Stock Market below I year with a percentage of $10.1 \%, 78$ fell in between $1-3$ with a percentage of $41.3 \%$. 73 were having an experience between 3-6 with a percentage of $38.6 \% .13$ were having an experience in between 6-12 years with a percentage of $6.9 \%$ and 6 having experience above then 12 years with a percentage of $3.2 \%$. Below Table 5 is the graphical representation of the table

From the above Table 7, it is apparent that out of 189 respondents 93 respondents were having monthly income below then 45000 with I year with a percentage of $49.2 \% .52$ were having monthly income fell in between $45001-65000$ with a percentage of $27.5 \% .27$ respondent were having monthly income fell in between $65001-85000$ with a percentage of $14.3 \% .6$ respondent were having monthly income fell in between 65001-85000 with a percentage of $3.2 \% .11$ respondent were having monthly income above 105000 with a percentage of $5.8 \%$.

\section{Descriptive statistics}

The descriptive analysis observes the trend of the data. The table shows the mean values, standard deviation, and the range of minimum and maximum statistics. The minimum and maximum shows the correctness of data and it should be in limits of 1 to 5 measurement scale of instrument. As shown above, the maximum and minimum values are in the range from 1 to 5 Likert scale. No values are exceeding the mentioned limits for all variables. The values of skewness must be between the acceptable range i.e. from -1 to +1 and values of kurtosis should range from +3 to -3 . If the data lies outside the stipulated range, it means the data is abnormal. In this case the data has to be normalized in order to make it eligible for further tests. It is evident that all the statistics of Skewness and kurtosis are within the acceptable range. So data collected for this study was normal. This is also first and foremost assumption of regression analysis [82].

\section{Reliability}

Ensuring the reliability of the research instrument is vital for the authentication of the results. In order to conduct the full survey, researchers first carried out the pilot testing for ensuring the reliability

\begin{tabular}{|l|c|c|c|c|}
\hline & Frequency & Percent & Valid Percent & Cumulative Percent \\
\hline $26-33$ & 32 & 16.9 & 16.9 & 16.9 \\
\hline $34-41$ & 61 & 32.3 & 32.3 & 49.2 \\
\hline $42-49$ & 65 & 34.4 & 34.4 & 83.6 \\
\hline Above 50 & 31 & 16.4 & 16.4 & - \\
\hline Total & 189 & 100 & 100 & 100 \\
\hline
\end{tabular}

Table 4: Age.

\begin{tabular}{|l|c|c|c|c|}
\hline & Frequency & Percent & Valid Percent & Cumulative Percent \\
\hline Matriculation & 82 & 43.4 & 43.4 & 43.4 \\
\hline Bachelors & 72 & 38.1 & 38.1 & 81.5 \\
\hline Masters & 35 & 18.5 & 18.5 & - \\
\hline Total & 189 & 100 & 100 & 100 \\
\hline Total & 189 & 100 & 100 & 100 \\
\hline \multicolumn{4}{|c|}{ Table 5: Education. }
\end{tabular}

\begin{tabular}{|l|c|c|c|c|}
\hline & Frequency & Percent & Valid Percent & Cumulative Percent \\
\hline Under 1 year & 19 & 10.1 & 10.1 & 10.1 \\
\hline 1-3 years & 78 & 41.3 & 41.3 & 51.3 \\
\hline 3-6 years & 73 & 38.6 & 38.6 & 89.9 \\
\hline 6-12years & 13 & 6.9 & 6.9 & 96.8 \\
\hline Above12 years & 6 & 3.2 & 3.2 & - \\
\hline Total & 189 & 100 & 100 & 100 \\
\hline \multicolumn{4}{|c|}{ Table 6: Experience. }
\end{tabular}

\begin{tabular}{|l|c|c|c|c|}
\hline & Frequency & Percent & Valid Percent & Cumulative Percent \\
\hline Below 45000 & 93 & 49.2 & 49.2 & 49.2 \\
\hline $45001-65000$ & 52 & 27.5 & 27.5 & 76.7 \\
\hline $65001-85000$ & 27 & 14.3 & 14.3 & 91 \\
\hline $85001-105000$ & 6 & 3.2 & 3.2 & 94.2 \\
\hline Above 105000 & 11 & 5.8 & 5.8 & - \\
\hline Total & 189 & 100 & 100 & 100 \\
\hline
\end{tabular}

Table 7: Income. 
Citation: Javed H, Bagh T, Razzaq S (2017) Herding Effects, Over Confidence, Availability Bias and Representativeness as Behavioral Determinants of Perceived Investment Performance: An Empirical Evidence from Pakistan Stock Exchange (PSX). J Glob Econ 5: 275. doi: 10.4172/23754389.1000275

Page 9 of 13

of the instrument and then conducted the complete survey on the basis of the results of reliability testing. It is basically a degree to which an assessment tool produces stable and consistent results which shows that the instruments give same results if the trials are repeated again and again. For pilot test, Cronbach's alpha values of 30 questionnaires was conducted and got the below mentioned satisfactory results above 0.7 and for complete survey of 189 questionnaires the reliability values complemented our prior results and all the variables were above 0.8 on Cronbach alpha scale. Cronbach alpha value ranges from 0.732 to 0.968 which shows the strong reliability of the data which is acceptable and considered good. According to Shelby [83] the value of Cronbach's alpha must be greater than 0.7. The results mentioned below also complement the findings. Shelby [83] stated in his study that the value of Cronbach alpha should be greater than 0.6 .

\section{Pilot Survey Test}

In complete survey test where Table 8 explains about the bias and investment Performance in terms of alpha.

\section{Regression assumption testing}

There are seven assumptions for regression testing which must be met so that regression can be run. In the following sections, all the assumptions are tested with their respective statistical and graphical data [83].

\section{Normality}

2. Linearity

3. Absence of outliers

4. Absence of serial correlation and auto correlation

5. Homoscedasticity

\section{Normal distribution of error terms}

7. Absence of multi-co linearity.

Normality: Before the application of any test, normality of the data is ensured in order to be eligible for further statistical testing [84]. This assumption is fulfilled by the above mentioned skewness and kurtosis values which were in range as mentioned in descriptive statistics. For Skewness the acceptable range is $(+1$ to -1$)$ and that of Kurtosis is $(+3$ to -3$)$.

Linearity: This assumption is tested through one of the most important tests, i.e., Correlation.

\section{Correlation Matrix}

The correlation is most important assessment tool used in research studies. This analytical tool is used to analyze the relationship between two or more variables. It explains the linearity between the variables under observation. The value of correlation ranges from -1.00 to +1.00 . The negative value of correlation explains the strong negative correlation while the positive value near +1.00 depicts the strong positive correlation [85]. A correlation coefficient of +1 points show strong linear relationship and the negative value represent negative linear relationship. The correlation of 0 indicates that there is no linear relationship between the two variables. If the value lies between $0-0.3$ then there is weak correlation. If the value lies between $0.31-0.7$ then there is moderate correlation and if the value lies between $0.71-1$ then there is strong correlation which is shown in Table 9.

The statistics of the table demonstrates a moderate positive significant relationship between the herding bias and perceived investment performance. The correlation between herding bias and perceived investment performance is $(0.619)$ showing that the investors who follow others in their investment decisions have also improved the performance of their investment. So there is significant impact of herding on performance.

The statistics of the second variable show a moderate positive significant relationship between the over confidence bias and perceived investment performance. The correlation between over confidence bias and perceived investment performance is $(0.510)$ showing that the investors who over emphasize their skills and abilities than the market risk their perceived investment performance is also improved. So according to the statistics of our study, there is significant positive impact of over confidence on perceived investment performance of stock market investors.

The statistics of the third variable shows a strong positive significant relationship between the representative bias and perceived investment performance [86]. The correlation between representative bias and perceived investment performance is $(0.700)$ showing that the investors who base their investment decisions on the superficial characteristics of the stocks, their perceived investment performance also improves. So according to the statistics of our study, there is significant positive impact of representative bias on perceived investment performance of stock market investors [87].

Absence of outliers: The box plot showing absence of outliers is attached in the Appendix 1.

\begin{tabular}{|c|c|c|c|c|c|c|c|c|}
\hline & \multirow{2}{*}{$\begin{array}{l}\text { MIN } \\
\text { Stat }\end{array}$} & \multirow{2}{*}{$\begin{array}{l}\text { Max } \\
\text { Stat }\end{array}$} & \multirow[t]{2}{*}{ Mean } & \multirow{2}{*}{$\begin{array}{c}\text { Std. Devi. } \\
\text { Statistic }\end{array}$} & \multicolumn{2}{|c|}{ Skewness } & \multicolumn{2}{|c|}{ Kurtosis } \\
\hline & & & & & Statistic & Std. Er & Statistic & Std. Er \\
\hline HB & 1.00 & 5.00 & 3.1023 & 1.22189 & -0.261 & 0.177 & -1.303 & 0.352 \\
\hline ОСВ & 1.00 & 4.75 & 2.8651 & 1.14491 & -0.089 & 0.177 & -1.573 & 0.352 \\
\hline$A B$ & 1.00 & 5.00 & 2.8351 & 1.14291 & -0.089 & 0.177 & -1.571 & 0.352 \\
\hline RB & 1.20 & 5.00 & 3.4169 & 1.11857 & -0.601 & 0.177 & -.921 & 0.352 \\
\hline PIP & 1.00 & 4.67 & 3.4056 & 1.24012 & -0.581 & 0.177 & -1.340 & 0.352 \\
\hline
\end{tabular}

Table 8: Descriptive statistics.

\begin{tabular}{|c|c|c|c|}
\hline S. No & Variable & Items & 3 \\
\hline 1 & Herding Bias & 4 & 0.963 \\
\hline 2 & Overconfidence Bias & 3 & 0.943 \\
\hline 3 & Availability Bias & 5 & 0.983 \\
\hline 4 & Representative Bias & 3 & 0.938 \\
\hline 5 & Perceived Investment Performance & 3 & \\
\hline
\end{tabular}

Table 9: Pilot survey test. 
Citation: Javed H, Bagh T, Razzaq S (2017) Herding Effects, Over Confidence, Availability Bias and Representativeness as Behavioral Determinants of Perceived Investment Performance: An Empirical Evidence from Pakistan Stock Exchange (PSX). J Glob Econ 5: 275. doi: 10.4172/23754389.1000275

Page 10 of 13

Absence of serial correlation: The relationship of observations is the serial correlation. Serial correlations are often found when next observation is dependent on previous one. This is tested by DurbinWatson statistics. If the value lies in the acceptable range of 1.5-2.5 then there is no problem of serial correlation. The value of Durbin-Watson was 2.240 so there is no problem of serial correlation [88].

Homoscedasticity: This assumption is tested through normal probability plot $(\mathrm{p}-\mathrm{p})$ plot. The P-P plot shows that homoscedasticity is there, one unit of IV is changing the DV with the constant units the other unit bringing. The data must not have heteroscedasticity, which is a serious concern. The Figure 4 and Appendix 2 shows that approximately many points are on the line and less point is away from the line. This assumption also fulfilled.

Normal distribution of error terms: This assumption is tested through histogram, the histogram for this study shows that the error terms are negatively skewed from the mean. So no normal distribution of error terms exists.

Absence of multi-co linearity: Multi co linearity is the most important assumption of regression to check whether the independent variable effect each other in addition to effect on dependent variable [89]. This can be harmful because all analysis will be affected due to this multi-co linearity effect. In our regression analysis there is absence of multi-co linearity, it is tested through two values. The VIF should not be greater than 4 and Tolerance values must not be less than 0.25 . Both criteria have been fulfilled, so there is no issue of multi-co linearity.

\section{Regression}

Before analyzing the tests of regression analysis the seven assumptions need to be fulfilled. The first assumption is normality of

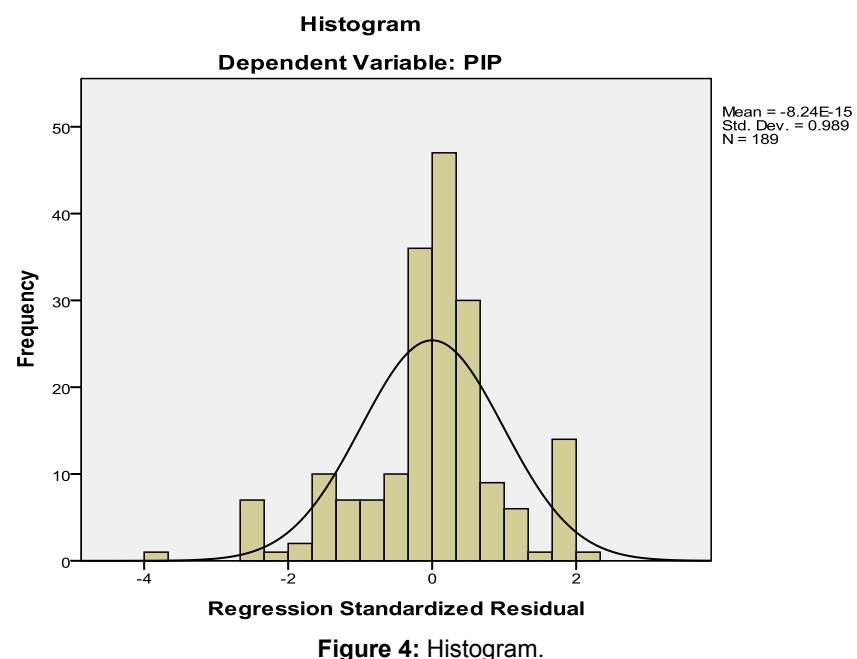

data and Table 10 shows that the Skewness values lies between -1 to +1 and Kurtosis values lies between -3 to +3 so this means that the data is normal. The second assumption is linearity of the data and Table 11 shows the linear trend of the data and the Linear relationship between the IVs and DVs. The third assumption is absence of outliers and from the Figure 2 it can be seen that there are no outliers so this assumption is also fulfilled. The fourth assumption is absence of serial and auto correlation so from table it can be seen that the Durbin Watson value is 2.240 and it lies between the range 1.5 to 2.5 so there is no auto and serial correlation. The fifth assumption is homoscedasticity and from Figure 1 it is tested through normal probability plot p-p plot. The P-P plot shows that homoscedasticity, one unit of IV is changing the DV with the constant units. As the above graph depicts that approximately many points are on the line and less points are away from the line. This assumption also fulfilled. The sixth assumption is normal distribution of error terms and this assumption is tested through histogram, the histogram for this study shows that the error terms are negatively skewed from the mean [90]. So no normal distribution of error terms exists and from Figure 2 it can be seen. The seventh assumption is absence of multi Co linearity, it can be seen that the tolerance and VIF values are fulfilling the assumption. The VIF values must be less than 4 and tolerance values must be above 0.25 . Our all the seven assumptions are fulfilled before regression analysis in the Table 12.

From table Model summary, the research hypotheses are tested by using regression analysis. The significance value is 0.000 which shows that our research model is significant and shows the strong regression between the behavioral biases and perceived investment performance. $\mathrm{R}$ is also called multiple correlation coefficients, the value of $\mathrm{R}=0.760$, it indicates that there is a strong correlation between behavioral biases and perceived investment performance. This statistic also contributes in the fitness of the model [91]. R square measures the proportion of variation in the dependent variable that is explained by the variations in independent variables. $\mathrm{R}$ square is the magnitude of the relationships it is the explanatory power of model, here the R square shows that $57 \%$ of the variation is explained. The adjusted $\mathrm{R}$ Square give the refine value of $\mathrm{R}$ square. Adjusted $\mathrm{R}$ square give the value after adjusting error term. The adjusted $\mathrm{R}$ square measures the proportion of variance in the dependent variable that was explained by the variations in independent variables, here the adjusted $\mathrm{R}$ square shows $57 \%$ variance is explained. The underline meaning is that remaining $43 \%$ of the variance in the dependent variable is due to other behavioral biases which are not in the scope of this study. Durbin Watson is 2.202 which measure the auto correlation between independent variables. Since the value lies between to $1.5-2.5$ so there is no problem of serial and auto correlation $[92,93]$.

The acceptance and rejection of our hypothesis are explained by the table of coefficients. The table shows some important statistics regarding the Independent Variables and their eligibility in impacting the dependent variable. According to the statistics, the Beta value of Herding bias (HB) is .283 which means that 1 unit change in $\mathrm{HB}$,

\begin{tabular}{|l|l|l|l|l|}
\hline & Herding Bias & Over Confidence & Availability Bias & Representative Bias \\
\hline Herding Bias & 1 & & & \\
\hline Over Confidence & $0.278^{* *}$ & 1 & 1 & \\
\hline Availability Bias & $0.378^{* *}$ & $0.456^{* *}$ & $0.536^{* *}$ & 1 \\
\hline Representative Bias & $0.685^{* *}$ & $0.582^{* *}$ & $0.452^{* *}$ & $0.700^{* *}$ \\
\hline $\begin{array}{l}\text { Perceived Investment } \\
\text { Performance }\end{array}$ & $0.619^{* *}$ & $0.510^{* *}$ & & 1 \\
\hline
\end{tabular}

${ }^{* *}$ Correlation is significant at the 0.01 level (2-tailed). 
Citation: Javed H, Bagh T, Razzaq S (2017) Herding Effects, Over Confidence, Availability Bias and Representativeness as Behavioral Determinants of Perceived Investment Performance: An Empirical Evidence from Pakistan Stock Exchange (PSX). J Glob Econ 5: 275. doi: 10.4172/23754389.1000275

Page 11 of 13

\begin{tabular}{|c|c|c|c|c|c|c|c|c|c|}
\hline \multicolumn{10}{|c|}{ Model Summary } \\
\hline $\mathbf{R}$ & R Square & $\begin{array}{c}\text { Adjusted R } \\
\text { Square }\end{array}$ & $\begin{array}{l}\text { Std. Error of the } \\
\text { Estimate }\end{array}$ & $\begin{array}{c}\text { R Square } \\
\text { Change }\end{array}$ & F Change & df1 & df2 & Sig. F Change & Durban Watson \\
\hline $0.760^{\mathrm{a}}$ & 0.578 & 0.571 & 0.81252 & 0.578 & 84.313 & 3 & 185 & 0.000 & 2.202 \\
\hline \multicolumn{10}{|c|}{ Predictors: $A B, R B, O C B, H B$} \\
\hline
\end{tabular}

Table 11: Model summary.

\begin{tabular}{|l|c|c|c|c|}
\hline Model & Sum of Squares & Df & Mean Square & \multicolumn{1}{|c|}{ Sig. } \\
\hline Regression & 166.99 & 3 & 55.663 \\
\hline Residual & 122.135 & 185 & 0.66 \\
\hline Total & 289.123 & 188 & \\
\hline aPredictors: AB,RB,OCB,HB & & \\
\hline
\end{tabular}

Table 12: Anova.

\begin{tabular}{|c|c|c|c|c|c|c|c|}
\hline \multirow[t]{2}{*}{ Model } & \multicolumn{2}{|c|}{ Unstandardized } & \multirow{2}{*}{$\begin{array}{c}\text { Standardized } \\
\text { Beta }\end{array}$} & \multirow[t]{2}{*}{$\mathbf{T}$} & \multirow[t]{2}{*}{ Sig. } & \multicolumn{2}{|c|}{ Co linearity statistics } \\
\hline & B & Std. Er & & & & Tolerance & VIF \\
\hline (Constant) & 0.250 & 0.208 & & 1.203 & 0.230 & & \\
\hline $\mathrm{HB}$ & 0.283 & 0.067 & 0.279 & 4.250 & 0.000 & 0.529 & 1.891 \\
\hline$A B$ & 0.285 & 0.065 & 0.265 & 4.250 & 0.000 & 0.549 & 1.892 \\
\hline OCB & 0.274 & 0.058 & 0.253 & 4.705 & 0.000 & 0.789 & 1.267 \\
\hline RB & 0.436 & 0.079 & 0.393 & 5.547 & 0.000 & 0.454 & 2.204 \\
\hline
\end{tabular}

Table 13: Coefficients.

\begin{tabular}{|c|c|c|c|c|}
\hline Hypothesis & Statements & Coefficient & $\begin{array}{c}P \text { value } \\
\text { Significant }\end{array}$ & Decision Status \\
\hline $\mathrm{H}_{1}$ & Herding effect has a positive impact on perceived investment performance. & 0.283 & 0.000 & Accepted \\
\hline $\mathrm{H}_{3}$ & Availability Bias has a positive significant impact on perceived investment performance. & 0.285 & 0.000 & Accepted \\
\hline $\mathrm{H}_{3}$ & Confidence has a positive impact on perceived investment performance. & 0.274 & 0.000 & Accepted \\
\hline $\mathrm{H}_{4}$ & Representativeness bias has a positive impact on investment performance. & 0.436 & 0.000 & Accepted \\
\hline
\end{tabular}

Table 14: Testing of hypothesis.

imparts .283 units change in the Perceived Investment Performance (DV). This means that when herding is done, investment performance also increases, showing positive relationship between the two variables. The $\mathrm{T}$ value is 4.250 which is greater than 2 so it is significant. The significance value is 0.000 which means that herding Bias has a significant positive impact on perceived investment Performance. The second variable is the over confidence Bias and the Beta value of $(\mathrm{OCB})$ is 0.274 which means that 1 unit change in $\mathrm{HB}$, imparts 0.274 units change in the Perceived Investment Performance (DV). This means that when over confidence is shown by an investor, investment performance also increases, showing positive relationship between the two variables. The $\mathrm{T}$ value is 4.705 which is greater than 2 so it is significant [94]. The significance value is 0.000 which means that over confidence Bias has a significant impact on perceived investment Performance. The third variable is the Representative Bias and the Beta value of (RB) is 0.436 which means that 1 unit change in RB, imparts 0.436 units change in the Perceived Investment Performance (DV). This means that when investors use representative bias in their investment, investment performance also increases, showing positive relationship between the two variables [95-97]. The $\mathrm{T}$ value is 5.547 which is greater than 2 so it is significant. The significance value is 0.000 which means that over Representative Bias has a significant impact on perceived investment Performance as shown in the Tables 13 and 14.

\section{Conclusion, Limitation and Future Implications}

The Behavioral Determinants (BD) of Perceived Investment Performance (PIP) are considered to be one of the most sizzling research concerns in the world of investment behavioral finance. Therefore, the main purpose of this study was to investigate the herding effects (HE) over confidence (OC) availability bias (OB) and representativeness (R) [Independent Variables] as BD of PIP [Dependent Variable] in case of Pakistan stock exchange (PSX). Specifically, this study amid at to identify which biases impact more on PIP and to identify useful insights from the results of the study that may benefit in this discipline. Five likert scale questionnaire adapted from prior studies as it is satisfying the current scenario for industry settings of PSX. A quantitative cross sectional research design has been used in this study. The regression results found that the herding effects, over confidence, availability bias and representativeness have positive and significant impact on perceived investment performance. This study has significance for the individual investors, financial advisors, companies listed in PSX and Government. For the investors, the factors that influence their investment performance are crucial as these will influence their financial plans of future. Practical implications includes investors who desires to invest should incorporate the said $\mathrm{BD}$ for the accurate valuation of the assets and in taking future investment decisions. In PSX, it is first endeavor to uncover the HE, OC, $\mathrm{AB}$ and $\mathrm{R}$ as $\mathrm{BD}$ of PIP. This paper contribute to the existing body of literature since main stream of the previous studies concentrate more on the developed countries markets of the world. Moreover, this study put forth a well-integrated model to probe the effect of variables under consideration on PSX. Reflection of the said effect of behavioral impact in the decision making process of individuals will make the decisions more optimal and rational as well.

\section{Future implications}

1. It is indispensable to conduct further research to confirm the findings of this research. 
Citation: Javed H, Bagh T, Razzaq S (2017) Herding Effects, Over Confidence, Availability Bias and Representativeness as Behavioral Determinants of Perceived Investment Performance: An Empirical Evidence from Pakistan Stock Exchange (PSX). J Glob Econ 5: 275. doi: 10.4172/23754389.1000275

Page 12 of 13

2. The model must be implemented and tested in case of further researches, for all the stock exchanges of Pakistan in a single comprehensive study.

3. Further research studies are suggested to incorporate the data collection from individual and institutional investors separately in order to demonstrate differences.

4. Future researches are recommended to explore the remaining behaviors with mediation of risk perception.

5. A larger sample size is suggested for future researches to improve the reliability of results and to increase the generalizability.

6. Financial literacy is recommended for future research models.

7. Personal interview technique should be implemented for data gathering from the subjects.

\section{Limitations}

1. Limited behavioral biases are used

2. Limited scope of this study due to limited financial resources

3. Researchers faced time constraints in data gathering.

\section{References}

1. Kim K, Nofsinger JR (2008) Behavioral finance in Asia. Pacific-Basin Finance Journal 16: 1-7.

2. Demirer R, Kutan AM (2006) Does Herding Behavior Exist in Chinese Stock Markets? Journal of International Financial Markets, Institutions and Money 16: 123-142.

3. Singh R (2009) Behavioural Finance: The Basic Foundations. Journal of Management 2: 89-98.

4. Waweru NM, Munyoki E, Uliana E (2008) The effects of behavioral factors in investment decision-making: a survey of institutional investors operating at the Nairobi Stock Exchange. International Journal of Business and Emerging Markets 1: 24-41.

5. Meditinos DI, Sevic Z, Theriou NG (2007) Investors' behavior in the Athens Stock Exchange. Studies in Economics and Finance 24: 32-50.

6. Evans DA (2006) Subject perceptions of confidence and predictive validity in financial cues. Journal of behavioral Finance 7: 12-28.

7. Gao L, Schmidt $L(2005)$ Self is never neutral: why economic agents behave irrationally. Journal of Behavioral Finance 6: 27-37.

8. Yaari ME (1987) The Dual Theory of Choice under Risk. Econometrica 55: 95-115.

9. Samuelson W, Zeckhauser R (1988) Status Quo Bias in Decision Making. Journal of Risk and Uncertainty 1: 1-59.

10. Szyszka A (2007) From the Efficient Market Hypothesis to Behavioral Finance How Investors' Psychology Changes the Vision of Financial Markets. Poznan University of Economics Press.

11. Morck R (2004) Behavioral finance importance. National Bureau of Economic Research.

12. Ritter JR (2003) Behavioral Finance. Pacific-Basin. Journal of Finance 11: 429-437.

13. Tan L, Chiang TC, Mason JR, Nelling E (2008) Herding behavior in Chinese stock markets: An examination of $A$ and $B$ shares. Pacific-Basin Finance Journal 16: 61-77.

14. Kahneman D, Tversky A (1974) Judgment under Uncertainty: Heuristics and Biases. Journal of Science 185: 1124-1131.

15. Zuravicky O (2005) The Stock Market: Understanding and applying ratios, decimals, fractions, and percentages. The Rosen Publishing Group, Inc.

16. Luu TT (2011) Organizational culture and trust as organizational factors for corporate governance. International Journal of Management and Enterprise Development 11: 142-162.
17. Samuel C (1996) Stock Market and Investment: The signaling Role of the Market. Policy research.

18. Teweles RJ, Bradley ES (1998) The Stock Market. John Wiley and Sons, Inc.

19. Jaswani T (2008) Function and Purpose of Stock Market.

20. Croushore D (2006) Money and Banking: A Policy oriented approach. Cengage Learning.

21. Sahi SK, Arora AP, Dhameja N (2013) An Exploratory Inquiry into the Psychological Biases in Financial Investment Behavior. Journal of Behavioral Finance 14: 94-103.

22. Yates JF, Zhu Y, Ronis DL, Wang DF, Shinotsuka H, et al. (1989) Probability Judgment Accuracy: China, Japan, and the United States. Organizational Behavior and Human Decision Processes 43: 145-171.

23. Hofstede G (1984) The Cultural Relativity of the Quality of Life Concept Academy of Management Review 9: 389-398.

24. Ricciardi V (2008) Risk: Traditional finance versus behavioral finance.

25. Ricciardi V (2008) The psychology of risk: The behavioral finance perspective.

26. Zhu N (2002) The Local Bias of Individual Investors. Yale ICF.

27. Montier J (2007) Behavioural investing: Apractitioner's guide to applying behavioral finance. Chichester, UK: JohnWiley \& Sons.

28. Weber EU (2004) Perception matters: Psychophysics for economists. Oxford University Press 2: 163-176.

29. Elke UW, Richard AM (1997) Perceived Risk Attitudes: Relating Risk Perception to Risky Choice. Management Science 43: 123-144.

30. Lane C, Quack S (1990) The social dimensions of risk: Bank financing of SMEs in Britain and Germany. Organization Studies 20: 987-1010.

31. Hong H, Kubik JD, Stein JC (2004) Social Interaction and Stock Market Participation. The Journal of Finance 59: 137-163.

32. Fromlet H (2001) Behavioral Finance-Theory and Practical Application Business Economics 36: 63-69.

33. Shefrin H (2000) Beyond Greed and Fear: Understanding Behavioral Finance and the Psychology of Investing. Boston: Harvard Business School Press.

34. Kahneman D, Tversky A (1979) Prospect theory: an analysis of decisions under risk. Econometrical 47: 263-291.

35. Simon HA (1957) Models of Man: Social and Rational. John Wiley \& Sons, Inc.

36. Barberis N, Thaler RH (2003) A Survey of Behavioral Finance. Elsevier Science, B.V.

37. Tesfatsion L (2006) Agent-Based Computational Economics: A Constructive Approach to Economic Theory. In: Handbook of Computational Economics, pp 831-880.

38. Ngoc LT (2014) Behavior Pattern of Individual Investors in Stock Market International Journal of Business and Management 9:1-15.

39. Khan MH (2014) An Empirical Investigation on Behavioral Determinants of Perceived Investment Performance; Evidence from Karachi Stock Exchange. Research Journal of Finance and Accounting 5: 129-137.

40. Qureshi SA, Rehman K, Hunjra Al (2012) Factors Affecting Investment Decision Making of Equity Fund Managers. Wulfenia Journal of management sciences 19: 280-291.

41. Melissa LF, Ali A, Paul S, Stephen MJ (2000) The Abet Heuristic in Judgments of Risks and Benefits. Journal of Behavioral Decision Making 13: 1-17.

42. Tversky A, Kahneman D (1973) Availability: A heuristic for judging frequency and probability. Cognitive Psychology 5: 207-232.

43. Sewell M (2010) Behavioral Finance. Working paper, University of Cambridge.

44. Amihud $\mathrm{Y}$, Mendelson H, Lauterbach B (1997) Market microstructure and securities values: Evidence from the Tel Aviv Stock Exchange. Journal of Financial Economics 45: 365-390

45. Sitkin SB, Pablo AL (1992) Reconceptualizing the determinants of risk behavior Academy of Management Review 17: 9-38.

46. Oberlechner T, Osler CL (2004) Overconfidence in currency markets. International Business School. 
Citation: Javed H, Bagh T, Razzaq S (2017) Herding Effects, Over Confidence, Availability Bias and Representativeness as Behavioral Determinants of Perceived Investment Performance: An Empirical Evidence from Pakistan Stock Exchange (PSX). J Glob Econ 5: 275. doi: 10.4172/23754389.1000275

Page 13 of 13

47. Kallinterakis V, Munir N, Markovic MR (2010) Herd Behavior, Illiquidity, and Extreme Market States: Evidence from Banja Luka. Journal of Emerging Market Finance 9: 305-324.

48. Tran VH (2007) Price limit regulation and herd behavior in Vietnamese stock market.

49. Goodfellow C, Bohl MT, Gebka B (2009) Together we invest? Individual and Institutional Investors Trading Behaviour in Poland. International Review of Financial Analysis 18: 212-221.

50. Shleifer A (2000) Inefficient markets: an introduction to behavioral finance. Oxford University Press.

51. Bettman JR (1973) Perceived Risk and Its Components: A Model and Empirical Test. Journal of Marketing Research 10: 184-190.

52. Gompers PA, Metrick A (2001) Institutional Investors and Equity Prices. The Quarterly Journal of Economics 116: 229-259.

53. Officer RR (1973) The variability of the market factor of the New York Stock Exchange. The Journal of Business 46: 434-453.

54. Prosad JM, Kapoor S, Sengupta J (2012) An Examination of Herd Behavior: An Empirical Study on Indian Equity Market. International Proceedings of Economics Development and Research 30: 11-15.

55. Landberg W (2003) Fear, greed and madness of markets: The Decisions Investors Make. Journal of Accountancy 195: 79-82.

56. Finucane ML, Alhakami A, Slovic P, Johnson SM (2000) The affect heuristic in judgments of risks and benefits. Journal of Behavioral Decision Making 13: $1-17$.

57. Barber BM, Odean T (1999) The courage of misguided conviction. Financial Analysts Journal.

58. Werner DB (1998) A Portrait of the Individual Investor. European Economic Review 42: 831-844

59. Barber B, Odean T (1999) The courage of misguided convictions. Financial Analysts Journal, pp: 41-55

60. Daniel K, Titman S (2000) Market efficiency in an irrational world. National Bureau of Economic Research (NBER) 55: 28-40.

61. Saunders M, Lewis P, Thornhill A (2009) Research methods for business students. Italy: Pearson Education Limited.

62. Ricciardi V, Simon H (2000) The case for behavioral finance: A new frontier The Northeast Business \& Economics Association.

63. Odean T (1998) Volume, volatility, price and profit when all trades are above average. Journal of Finance 53: 1887-1934.

64. Anderson A, Henker J, Owen S (2005) Limit Order Trading Behavior and Individual Investor Performance. The Journal of Behavioral Finance 6: 71-89.

65. Michael P (2008) Organized uncertainty: Designing a world of risk management. New York: Oxford University Press.

66. Bracha A, Donald JB (2012) Affective Decision Making: A Theory of Optimism Bias. Games and Economic Behavior 75:67-80.

67. Steen EV(2002) Skill or Luck? Biases of Rational Agents. Massachusetts Institute of Technology (MIT), Sloan School of Management, pp: 1-39.

68. Ghauri P, Gronhaug K (2010) Research methods in business studies. Fourth edition. Great Britain: Pearson Education Limited.

69. Weber EU (2010) Risk Attitude and Preference. Wiley Interdisciplinary Reviews: Cognitive Science 1: 79-88.

70. Wang AF (2001) Overconfidence, Investor Sentiment and Evolution. Journal of Financial Intermediation 10: 138-170.

71. DeBondt WFM, Thaler RH (1995) Financial Decision-Making in Markets and Firms: A Behavioral Perspective. Operations Research and Management Science 9: 385-410.
72. Shefrin $\mathrm{H}$ (2009) Ending the management illusion: Preventing another financial crisis. Ivey Business Journal 73:1-7.

73. Tversky A, Kahneman D (1971) The belief in the law of small numbers. Psychological Bulletin 76: 105-110.

74. Olsen RA (2007) Investors predisposition for annuities: A psychological perspective. Journal of Financial Service Professionals 61: 51-57.

75. Lin A, Swanson P (2003) The Behavior and Performance of Foreign Investors in emerging Equity Markets: Evidence from Taiwan. International Review of Finance 4: 189-210.

76. Busenitz LW (1999) Entrepreneurial risk and strategic decision making: It's a matter of perspective. The Journal of Applied Behavioral Science 35: 325-340.

77. Falconer $L$ (2002) The influences of risk perception. University of Bath.

78. Merilkas A, Prasad D (2003) Factors influencing Greek investor behavior on the Athens stock exchange. Annual Meeting of the Academy of Financial Services, Denver, USA.

79. Sharma V (2004) Two Essays on Herding in Financial Markets. Virginia polytechnic Institute and State University.

80. William (2006) The Research Methods Knowledge Base.

81. Hair JF, Black B, Babin B, Andersion RE, Tatham RL (1998) Multivariate data analysis. Kennesaw State University.

82. Bryman A, Bell E (2007) Business Research Methods. Oxford University Press

83. Shelby LB (2011) Beyond Cronbach's Alpha: Considering Confirmatory Factor Analysis and Segmentation. Human Dimensions of Wildlife 16: 142-148.

84. Barber BM, Ordean T (2008) All That Glitters: The Effect of Attention and News on the Buying Behavior of Individual and Institutional Investors. The Review of Financial Studies 21: 785-818.

85. Luca C (2008) Back-to-basics on the defensive: Now what for the risk profession? Journal of Risk Management in Financial Institutions 1: 452-457.

86. Cary AD, Jungmin L, Javier AR, Chris R (2008) Measuring Risk Attitudes Controlling for Personality Traits. Economics Research Working Paper Series.

87. Diacon S, Ennew C (2001) Consumer perceptions of financial risk. The Geneva Papers in Risk \& Insurance: Issues \& Practice 26: 389-409.

88. Goto S (2007) The bounds of classical risk management and the importance of a behavioral approach. Risk Management \& Insurance Review 10: 267-282.

89. Felix K (2008) What are we missing in risk management? Journal of Risk Management in Financial Institutions 1: 354-359.

90. Patrick MC (2008) People risk: Where are the boundaries? Journal of Risk Management in Financial Institutions 1: 370-381.

91. Ricciardi V (2004) A risk perception primer: A narrative research review of the risk perception literature in behavioral accounting and behavioral finance.

92. Ricciardi $V$ (2006) A research starting point for the new scholar: A unique perspective of behavioral finance. ICFAI Journal of Behavioral Finance 3: 6-23.

93. Robson C (2002) Real World Research: A Resource for Social Scientists and Practitioner-Researchers. Oxford: Blackwell, UK.

94. Schwartz H (1987) Perception, judgment, and motivation in manufacturing enterprises: Findings and preliminary hypotheses from in-depth interviews. Journal of Economic Behaviour and Organization 8: 543-565.

95. Schwartz H (1998) Rationality Gone Awry? Decision Making Inconsistent with Economic and Financial Theory. Greenwood Publishing Group, USA.

96. Sitkin SB, Weingart LR (1995) Determinants of risky decision-making behavior a test of the mediating role of risk perceptions and propensity. Academy of Management 38: 1573-1592.

97. Weber UE, Blais RE, Betz NE (2002) A domain-Specific Risk Attitude Scale: Measuring risk perceptions and risk behaviors. Journal of Behavioral Decision Making 15: 263-290. 